\title{
Nuevos planteamientos museográficos en los museos de arte contemporáneo: \\ de las primeras críticas al museo en los albores del siglo XX a los actuales "microrrelatos"
}

\author{
New Museological Approaches in Contemporary Art Museums: \\ From the First Critiques of the Museum in the Early Twentieth Century \\ to Today's "Micronarratives"
}

\author{
Laura Arias Serrano \\ Departamento de Historia del Arte III (contemporáneo) \\ Facultad de Geografía e Historia. Universidad Complutense de Madrid \\ larias@ucm.es
}

Recibido: 29-09-2014

Aceptado: 10-11-2014

\section{RESUMEN}

Este articulo realiza un recorrido por algunas de las criticas y debates que, en torno al museo y a su forma de mostrar las colecciones, se han sucedido a lo largo de los siglos XX y XXI. Reflexionaremos para ello sobre la dificil y ambigua relación que el arte más actual y, por extensión, los museos de arte contemporáneo, han mantenido con el público y los artistas.

Palabras Clave: Arte contemporáneo. Museografía. Crítica al museo. Micro-relatos. Público.

\section{Abstract}

This article takes a tour by some of the reviews and discussions that have occurred along the XX and XXI centuries around the museum, and its way of showing collections. For it we will reflect on the difficult and ambiguous relationship that most current art and, by extension, contemporary art museums, have maintained with the audience and the artists.

KeY words: Contemporary art. Museology. Critical to the museum. Micro-relatos. Public. 


\section{Los museos de arte contemporáneos y su ambigua relación con el público y los artistas}

Los museos de arte contemporáneo, o mejor deberíamos decir "de arte moderno", son los que más han evolucionado en el tiempo. Algo lógico pues fueron ellos los que dieron cobijo a las vanguardias de principios del XX y a los movimientos rupturistas que las siguieron, caracterizados por su individualismo, sus planteamientos anteclásicos y su hermetismo intelectual. Museos que, con frecuencia, acogen una gran diversidad de manifestaciones artísticas (pintura, escultura, fotografía, videos, instalaciones...), necesitando por ello espacios asépticos, diáfanos y flexibles. Museos, en definitiva, que, pese a mostrar un discurso expositivo complejo, suelen despertar una gran expectación social, como en su día ocurrió con las vanguardias.

Precisamente, en esta ambigua relación de "atracción-repulsión" que, desde principios del siglo XX, el arte más actual y por extensión los museos de arte contemporáneo, han mantenido con el público y los artistas, es donde vamos a situar nuestras reflexiones. Tomamos como referencia, por un lado, las críticas y debates contra el museo que fueron sucediéndose a lo largo de la pasada centuria, y, por otro, las estrategias de comunicación llevadas a cabo por los responsables de la institución, como forma de tender puentes entre el público y el museo; estrategias no siempre efectivas ni para el visitante de a pie ni tan siquiera para el que se supone iniciado.

La primera crítica importante al museo tuvo lugar a comienzos del XX, cuando algunos artistas vanguardistas empezaron a verlo como una institución enciclopédica e ilustrada, como un obsoleto almacén repleto de obras de arte descontextualizadas e investidas de una falsa solemnidad. Algo que también compartía el poeta y escritor italiano Filippo Tommaso Marinetti (1978:132), quién en su Manifiesto futurista de 1909 escribía:

Italia ha sido durante muchos años la bolsa de los chamarileros, y nosotros queremos desembarazarla de sus museos innumerables, que la cubren de innumerables cementerios. Museos: ¡cementerios!... Idénticos verdaderamente en su siniestra promiscuidad de cuerpos que no se conocen. Dormitorios públicos donde se duerme para siempre junto a otros seres odiados o desconocidos. Ferocidad recíproca de los pintores y de los escultores, destruyéndose mutuamente a líneas y pinceladas en el mismo museo.

Esta inutilidad del museo y sus múltiples contradicciones son asimismo puestas sobre el tapete por destacados literatos, como el poeta y ensayista Paul Valéry, quien en su breve pero brillante artículo, "Le problème des musées" (1923), nos cuenta sus sensaciones durante la visita a un museo, que para Adorno (2008:160) quizá se trate del caótico y abarrotado Louvre, y cuya frialdad y confusión acabará asociando al vértigo de la vida moderna:

No me gustan demasiado los museos... Al primer paso que doy hacia las cosas bellas, una mano me arranca el bastón, un rótulo me prohíbe fumar.

Enfriado por el gesto autoritario y el sentimiento de coerción penetro en alguna sala de escultura donde reina una confusión fría... Estoy en un tumulto de criaturas congeladas donde cada una pide, sin obtenerla, la inexistencia de todas las demás...

Dispuesta el alma a cualquier pena, me adentro en la pintura. Ante mí se despliega en silencio un extraño desorden organizado. Soy presa de horror sagrado... Pronto dejo de saber a qué he venido a estas soledades enceradas, con algo de templo y de salón, de cementerio y de escuela... Salgo con la cabeza molida y las piernas tambaleantes de ese templo de los placeres más nobles... El magnífico caos del museo me sigue y se combina con el movimiento de la calle viva. Mi malestar busca su causa. Percibe, o inventa alguna imprecisa relación entre esa confusión que le obsesiona y el estado tormentoso de las artes de nuestro tiempo (Valéry 1999:137-140).

Pero al museo también se le reprochaba su museografía obsoleta, su visión estática de la historia, su manía acumulativa y su ceguera a la hora de dar a conocer el arte nuevo (Bolaños 2006: 8). Una situación de desamparo que propició que el arte de vanguardia acabara encontrando su lugar, más que en el museo, en la casa de algún coleccionista amante de lo nuevo o de algún arriesgado marchante. Y lo mismo ocurrió con los artistas, que se lanzaron a organizar de espaldas al museo sus propias exposiciones, como forma de dar a conocer y legitimar sus obras.

Pensemos, por ejemplo, en las exposiciones surrealistas de 1938 y 1942 en París y Nueva 


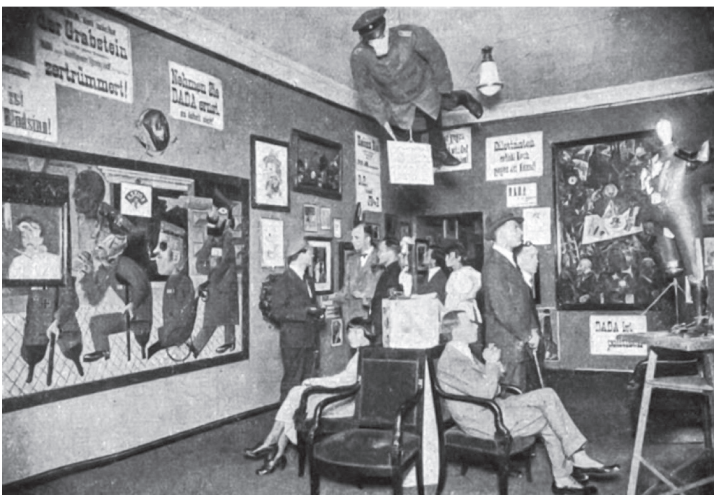

Fig. 1. Primera Feria Internacional Dada (1920). Galería Otto Burchadt. Berlin. El segundo por la derecha es Grosz, y sentado se encuentra Heartfield[Imagen: World War I and Dada, Moma Learning] [URL:http://www.moma.org/learn/ moma_learning/themes/dada].

York, verdaderos antecedentes de las actuales "instalaciones". O en la Primera Feria Dada de 1920, donde los artistas Hausmann, Heartfield y Grosz, como critica a la República de Weimar y a su aburguesada concepción del arte, organizaron una provocativa puesta en escena donde las obras de arte aparecían mezcladas de forma caótica con grabaciones musicales, carteles, fotomontajes, extraños maniquíes colgados del techo..., creando una terrible sensación de vértigo y tensión en el espectador (Fig. 1).

\section{Un nuevo concepto de museo: el Museo moderno}

Estas extravagantes iniciativas y el descrédito que vivía el museo tradicional propiciaron que desde los años veinte y treinta empezara a tomar forma en Norteamérica un nuevo concepto de museo: el Museo Moderno, apoyado por el joven historiador del arte Alfred H. Barr, desde su puesto de director del Museo de Arte Moderno de Nueva York (MoMA).

En una entrevista de 1993, Philip Jhonson (Bolaños 2002:129), conservador de arquitectura de dicho museo, recordaba cómo el propio Barr había viajado por Europa para conocer las últimas tendencias museológicas, sorprendiéndole gratamente la Alemania de Weimar, y en especial el Museo Folkwang de Essen, donde primaba la austeridad en la forma de disponer los cuadros: colgados muy bajos, contra un fondo neutro y $\sin$

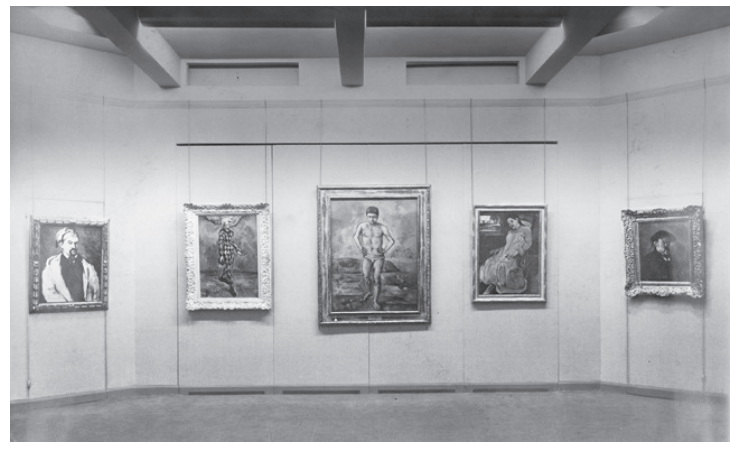

Fig. 2. Vista de la primera exposición del MoMA dedicada a Cézanne, Gauguin, Seurat y Van

Gogh(noviembre- diciembre, 1929). [Imagen: Hugendubel, Eleonore, Small Steps Lead to Bigger Changes: MoMA's Shifting Wall Colors, Inside out, 2010/03/11]. [URL:http://www.moma.org/explore/ inside_out/inside_out/wp-content/uploads/2010/03/ Installation-view-1929.sm_1.jpg].

ningún tipo de adorno. Esto hizo que, cuando en el otoño de 1929 el MoMA mostró por primera vez sus colecciones al público, las pinturas, ubicadas en pequeñas estancias pintadas de blanco, lejos de abarrotar las paredes hasta el techo, se colgaran en una sola fila, a la altura de los ojos y con un amplio espacio intersticial, lo que les permitía respirar, y facilitaba su disfrute y contemplación. (Fig. 2)

Nacía así el White Cube o Cubo blanco, un espacio neutro, abstracto y desornamentado que terminaría por convertirse en el marco más adecuado para exponer arte moderno:

La creación del cubo blanco, espacio prístino que no está en ningún sitio, es uno de los hallazgos de la modernidad: un hallazgo comercial, estético y tecnológico... Responde a la imagen de la sociedad que la promueve, de modo que es una superficie idónea desde la que devolver, rebotando, nuestras paranoias (O'Doherty 2011: 74).

También fue Barr el primero que dejó entrar en las colecciones del museo obras que tradicionalmente no se consideraban artísticas, como la fotografía, el diseño gráfico e industrial u otro tipo de objetos ${ }^{1}$, que por su capacidad de contextualizar inspirarían las futuras "micro-narraciones" llevadas a cabo por otros museos.

Tampoco quiso restringir sus compras y sus exposiciones a obras ya consagradas, compro- 
metiéndose por el contrario con el arte nuevo y experimental, pues, según escribe el crítico de arte Irving Sandler en la introducción del libro La definición del arte moderno:

el museo había de ser una Kunsthalle que exhibiera las últimas obras, al tiempo que un Kunstmuseum o colección permanente. Resultaba arriesgado, y Barr lo sabía, pero merecía la pena correr el riesgo para evitar que el Museo se convirtiera en una tumba del arte (Barr 1989:11).

Este deseo de estar al día no evitó que a finales de los años sesenta el MoMA, paradigma de museo innovador, que desde los años treinta ejercía una autoridad capaz de conformar el relato de la historia del arte, se colocara en el punto de mira de las críticas más radicales, que pondrían en tela de juicio su utilidad y sentido, al demostrar que la lectura canónica que hacía de las vanguardias no era suficiente, pues terminaba "excluyendo" muchas cosas.

Sin duda, a finales de los años sesenta o principios de los setenta, y coincidiendo con una quiebra en el orden internacional nacido del capitalismo, al que ahora se enfrentaban distintos sectores sociales, había empezado a tomar fuerza una segunda oleada de descrédito hacia el museo. Prueba de ello fue la conocida revuelta estudiantil de Mayo del 68, que entre otras cosas criticaba el autoritarismo de las instituciones culturales, y la inutilidad de los museos:

a la consigna de ¡la Gioconda al metro!, los conservadores de museos desertaron de sus obligaciones, los artistas se negaron a exponer en las instituciones públicas y las galerías de arte cerraron sus puertas. [...] La crisis y agonía del museo, considerado un anacronismo alienante y autoritario, fue denunciada con alegre insistencia. El abismo que se había abierto entre el arte y el espacio museístico era insalvable (Bolaños 2006:12).

La primera respuesta a esta crítica institucional llegó de manos de la Nueva Museología (nouvelle muséologie), corriente que triunfó en Francia en los años setenta bajo la influencia del Frente Popular y sus ideas sobre la democratización de la cultura (Zubiaur 2004: 53). Apoyada por prestigiosos profesionales de museos, como el profesor Georges Henri Rivière, proponía un tipo de museo en donde el interés por el objeto fuera desplazándose hacia la comunidad (Hernández 1994: 74). Un museo vivo y participativo que se definía por el contacto directo entre el público y los objetos mantenidos en su contexto, recurriendo para ello a un lenguaje museográfico que facilitara la comprensión de las piezas expuestas. Esto explica que la nouvelle muséologie tuviera más éxito en los museos etnográficos que en los de arte, pues el objeto etnográfico sólo se entiende con el apoyo de documentos complementarios (Zubiaur 2004: 53).

En el polo opuesto se situaban los museos de arte moderno, y esa serie de corrientes post vanguardistas que rompían radicalmente con el concepto tradicional de obra de arte y con su presencia en el museo: desde el $O p$ - $A r t$, el minimalismo y el arte povera, al Pop-Art, al hiperrealismo y al arte conceptual con todo su abanico de efímeras manifestaciones: happening, performance, assemblages, instalaciones, body art, land art, intervenciones urbanas... Propuestas que, por su inmaterialidad o su carácter fugaz, su inmenso tamaño o porque no eran transportables al formar parte del cuerpo del artista, eran "voluntariamente" incompatibles física y conceptualmente con el museo. Y es que, como recordaba Bolaños (2000: 16), no se puede colgar un acontecimiento.

Además, muchas de estas obras trataban de denunciar la complicada situación social, política o humana que vivía el hombre actual: la problemática de las minorías, el racismo, la homosexualidad o el papel de la mujer en la sociedad, la represión política, la censura, la violencia, etc.

Era lógico que, en este contexto, los artistas acabaran rechazando el "Cubo blanco", por considerar que el mundo real, cambiante y conflictivo, no encajaba en ese lugar, demasiado pequeño, demasiado aséptico, demasiado sacralizado...

Pero "salir del cubo" suponía igualmente salir del mercado y sobre todo salir del museo, de ahí que los artistas empezaran a conquistar la calle: mostrando sus obras en antiguas fábricas, naves industriales, mataderos, viejas estaciones de trenes..., o bien, instalando su estudio en un almacén, en una escuela abandonada o en un taller de automóviles (Bolaños 2006: 12), pensaban que sólo así su arte podría conservar su carga de denuncia y su libertad.

También ahora algunos artistas, vinculados a la crítica institucional, empezaron a preguntarse qué es lo que ocurría con sus obras cuando salían del estudio y llegaban al museo o a la galería..., en qué consistía exactamente el "sistema del 
arte", cuál era el papel que en él jugaba el artista... Ante tal situación muchos de ellos empezaron a concebir sus trabajos como la mejor manera de promover el conocimiento crítico del museo, con el fin de transformarlo. Por ejemplo, entre 1968 y 1972, el artista belga Marce Broodthaers organizó una serie de exposiciones, alguna de ellas en su propio estudio, que emulaban un museo ficticio, a través del cual denunciaba los comportamientos y prácticas engañosas del museo, y el poder que tiene el mercado sobre el arte y los artistas.

Muy reveladoras fueron asimismo las críticas al museo que los artistas lanzaron desde la propia institución, lo que demostraba que también el museo empezaba a amoldarse al espíritu de su época, recobrando su monopolio en la difusión del arte. Así, el pionero de la crítica institucional, el alemán Hans Haacke, logró con su instalación MoMA Poll, realizada en 1970 por encargo del MOMA, criticar no sólo a algunos miembros del consejo de administración del museo, sino a la propia institución que lo había contratado.

\section{El paradigma del Pompidou y sus contro- versias}

Será en este contexto cuando Francia intente también recuperar el liderazgo artístico que, tras la Segunda Guerra Mundial, Estados Unidos le había arrebatado. Y lo hará a través de una institución que buscaba convertirse en el modelo alternativo al MoMA, dando respuesta al mismo tiempo a las aspiraciones planteadas por el Mayo francés. Nos referimos al Centre National d'Art et Culture Georges Pompidou de París, creado en 1977 por Renzo Piano y Richard Rogers, y que albergaba en su interior el Museo Nacional de Arte Moderno (MNAM), con una de las colecciones de arte del siglo XX más completas del mundo.

Aunque su estridente y psicodélica arquitectura, que dejaba a la vista tuberías, respiraderos y escaleras mecánicas, desató una fuerte expectación, y su estructura flexible y transparente lo convertían en un centro pluridisciplinar abierto a la ciudad y adaptado a las necesidades actuales, la forma en que se organizaron en el MNAM las colecciones no fue tan novedosa, emulando en algunos aspectos al museo neoyorquino. Según recoge J.P. Lorente (2008: 283-287), su director, el sueco Pontus Hulten, dividió el espacio con gruesos paneles, donde se colgaban los cuadros,

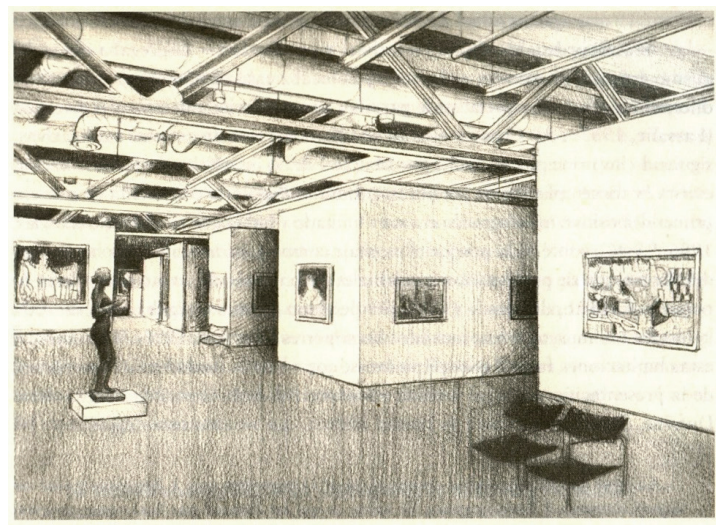

Fig. 3. Museografía original que combina recoletas cabanes con diáfanas explanadas. Museo Nacional de Arte Moderno. Centro Georges Pompidou. Paris. Dibujo de Francisco Javier Hernández para el libro de Lorente (2008: 285).

que iban conformando pequeñas unidades cerradas por tres lados y abiertas por uno. Estos cubículos más íntimos o cabanes en sucesión laberíntica se combinaban con zonas diáfanas y amplias, evocando, según el deseo de su director, amante del arte africano, un poblado de cabañas (Fig. 3). Quería ofrecer a los visitantes un espacio expositivo para distintos niveles de interés, curiosidad y fatiga, permitiéndole pasear sin itinerario prefijado. Esto, que fue su mayor virtud, también fue su mayor defecto, pues muchos visitantes, sobre todo si no disponían de demasiado tiempo, se angustiaban porque se perdían o dejaban de ver cosas que les hubieran gustado, o porque el estricto orden cronológico -se ordenaban por fecha de producción- hacía que las obras de un mismo artista o escuela se mezclaran con otras muy diferentes, creándoles gran confusión. Al final solo los especialistas acabarían valorando estas asociaciones como interesantes o divertidas.

Para enmendar estas cuestiones, en 1982, Dominique Bozo, tras suceder a Hulten como director, encargó a la diseñadora de interiores italiana Gae Aulenti reordenar las colecciones. Sin embargo, y al igual que le había ocurrido al MoMa, tampoco el museo francés logró liberarse de la idea de historia y mitificación de antaño, pues, mientras que la tercera planta (hoy Nivel 4), dedicada a los trabajos más contemporáneos, de 1960 a la actualidad, conservó el diseño museográfico original, la cuarta (hoy Nivel 5) mostraba las obras clásicas del "arte moderno", de 1905 a 1965 , en una instalación permanente, comparti- 
mentada en tramos cerrados, al estilo del White cube neoyorquino, ordenados como los capítulos de un libro de historia del arte. Aunque, al eliminar el recorrido libre, se acabó con la desorientación de los visitantes, esta rígida organización espacial acentuaba la idea de permanencia y consagración (Layuno 1997: 347), consiguiendo que las piezas recuperaran su protagonismo como obras de arte en sí mismas, como era usual en el museo tradicional.

Pero lo que el Pompidou sí consiguió, con su aspecto de gaseoducto o refinería petrolífera, destacando en pleno corazón de París, fue atraer a avalanchas de público, convirtiéndose en un verdadero espectáculo de masas. Esto no evitó que algunos entendidos, como fue el caso del sociólogo francés Jean Baudrillard (1978: 85), lanzaran contra él sus más aceradas críticas, al verlo como una simple moda, como un simulacro de consumismo cultural:

En un escenario museístico que sólo sirve para salvar la ficción humanista de la cultura, se lleva a cabo un verdadero asesinato de ésta, y a lo que en realidad son convidadas las masas es al cortejo fúnebre de la cultura. Y las masas acuden. Es la suprema ironía de Beaubourg: las masas se vuelcan no porque les crezca la saliva ante una cultura que las viene frustrando siglo tras siglo, sino porque por primera vez tienen ocasión de participar multitudinariamente en el inmenso trabajo de enterrar una cultura que en el fondo siempre han detestado.

Es precisamente en este contexto en el que, a mediados de los años ochenta, nació lo que hoy conocemos como Museología crítica: una corriente centrada fundamentalmente en los museos y centros de arte contemporáneo, que triunfó en Norteamérica y en el Reino Unido, frente a la Nueva Museología, más propia de áreas francófonas e interesada por los ecomuseos (Lorente 2006: 27).

Esta tendencia posmoderna y "revisionista", que ha perdurado hasta nuestros días, entiende los museos como comunidades de aprendizaje, más que como instituciones (Padró 2003: 60), museos que posibilitan múltiples miradas porque reconocen el papel subjetivo de lo expuesto, y en donde la cultura dominante, al quedar desmitificada y desestructurada, termina siendo más permeable a otros pueblos y culturas. No olvidemos que, a lo largo de la segunda mitad del siglo XX, se habían ido asentando en el corazón mismo de la civilización blanca, gentes procedentes de los continentes recién descolonizados (hindúes y caribeños en Inglaterra, turcos y europeos del Este en Alemania, magrebíes en Francia, hispanos, negros y orientales en Estados Unidos). Los excluidos, los desplazados... habían ido tomando la palabra imponiendo "otros" valores, otros cánones estéticos, otras formas de verdad que acabarían por sacudir al viejo Occidente (Bolaños 2000: 17).

Aunque en este escenario cambiante y globalizado que caracteriza al nuevo milenio, el museo, adaptado ya a los nuevos tiempos, goza de una popularidad sin precedentes, también lo vemos debatiéndose entre las luces y las sobras de sus propias contradicciones, derivadas en buena medida de esa irresistible tentación que produce el éxito mediático y el calor de las multitudes. Tanto es así que en las últimas décadas se han creado bastantes museos sin colección, bien porque sólo quieren coleccionar arte de la última generación (para luego venderlo o transferirlo), bien porque sólo piensan en organizar exposiciones, lo que los sitúa más cerca de una mera Kunsthalle que de la concepción tradicional de museo (Lorente 2008: 292).

Afortunadamente, en muchos museos aún pervive ese afán de búsqueda y confrontación propio del pasado siglo. Prueba de ello son los novedosos planteamientos museográficos que han empezado a imponerse en los últimos tiempos, basados en la búsqueda de la descontextualización y de lo ahistórico, en la mezcla de autores, obras, épocas, estilos o especialidades a la hora de mostrar las colecciones al público. Lo que favorece el intercambio de saberes, las interpretaciones cruzadas o las conexiones fragmentarias. Planteamientos, en definitiva, que obligan al espectador a implicarse, completando o, mejor dicho, generando "su propio discurso".

Estas insólitas propuestas museográficas han tenido su origen en la Tate Modern de Londres, un nuevo centro museístico de arte contemporáneo, ubicado en una antigua fábrica de electricidad rehabilitada, que nació en el año 2000 de la escisión de la Tate Gallery ${ }^{2}$, con la intención de convertirse en el museo de referencia del siglo XXI.

Siguiendo el criterio del entonces responsable del nuevo museo, el danés Lars Nittve, y del director del grupo Tate, Nicholas Serota, en un primer momento la colección se organizó en torno a cuatro temas: paisaje, pintura de historia, des- 
nudo y naturaleza muerta. Cuatro conceptos que interpretados desde la contemporaneidad permitían lecturas fragmentarias, discontinuas y abiertas, relatos que se descomponían en historias más pequeñas, y que a su vez cambiaban de sentido, se yuxtaponían o superponían en función del recorrido elegido por el visitante. Se planteaba así una manera menos contemplativa de mostrar el arte, traduciéndolo, no desde criterios formalistas, sino fundamentalmente temáticos y conceptuales.

En 2006, a los seis años de la apertura del museo, y con el fin de que minimizaran las críticas de algunos sectores de la prensa a quienes la presentación actual les parecía diseñada exclusivamente para especialistas (Tejeda 2009:42-43), el español Vicente Todolí, que ocuparía la dirección de la Tate Modern de 2002 a 2010, reordenó la colección de forma más didáctica y clara, evolucionando hacia un modelo temático algo más conservador, que, retomando la idea de continuidad en el tiempo, se centraba en episodios clave fácilmente reconocibles por el público: Gestos materiales (Abstracción y Expresionismo), Poesía y sueños (Surrealismo), Estados de flujo $(\mathrm{Cu}-$ bismo, Futurismo, Vorticismo y Pop Art) e Idea y objeto (Minimalismo). Un programa permanente, que se completaba con un amplio abanico de exposiciones temporales dedicadas en su mayoría a un solo autor.

Aunque parezca paradójico, lo más negativo de la Tate Modern hoy en día es el haberse convertido en un fenómeno mediático sin precedentes, en buena medida gracias a los impactantes proyectos llevados a cabo en la inmensa Sala de las Turbinas, que actúan de cebo para un público casi siempre más interesado por el espectáculo que por el arte. (Fig. 4)

La fascinación que en nuestra época siguen suscitando las nuevas fórmulas de presentación expositiva, vuelven a llevarnos a Francia y en concreto al Centro George Pompidou. Allí, en 2009, el Museo de Arte Moderno cambió de nuevo la organización de sus salas, recurriendo en esta ocasión a auténticas "micro-localizaciones" que introducían en el recorrido del visitante otros aspectos de la historia del arte: la Bauhaus, los Ballets Rusos, el cine, la fotografía..., una manera más de entender las relaciones que los objetos establecen entre sí a la hora de conformar el tejido histórico de una época.

Hay que destacar asimismo la importancia que actualmente tienen en el discurso del museo aquellas colecciones que en sí mismas conforman

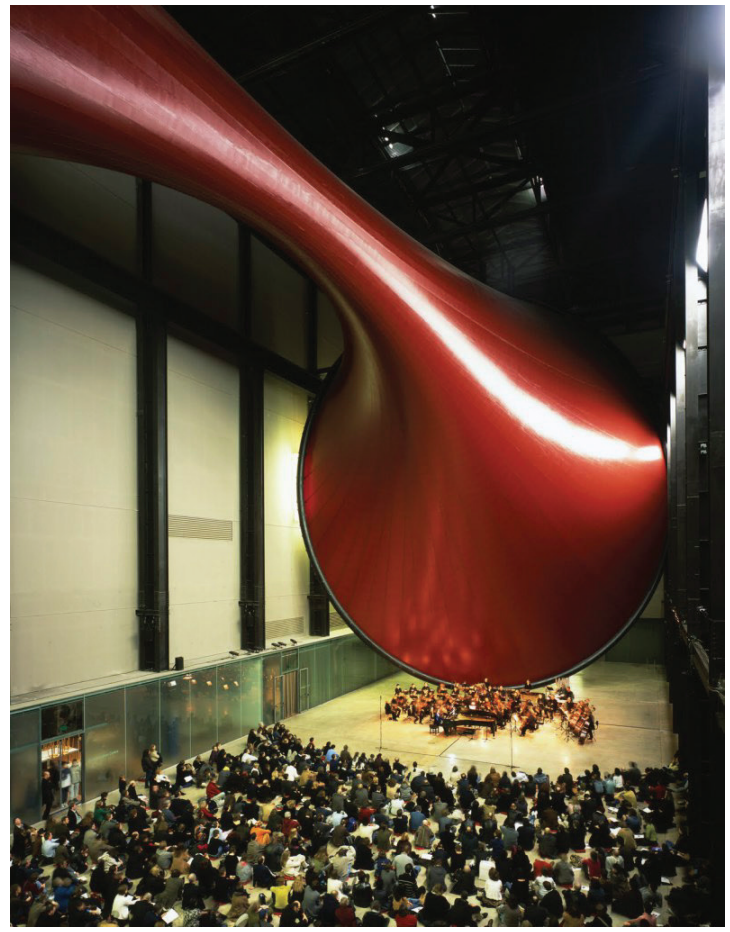

Fig. 4. Intervención de Anish Kapoor en laSala de Turbinas. Tate Modern de Londres. [Imagen: Anish Kapoor, nodisparenalartista.wordpress.com, 2012/09/21]. [URL:http://nodisparenalartista.wordpress.com/2012/09/21/anish-kapoor/].

una historia o sirven para ilustrar a un personaje. Pensemos, por ejemplo en Le Mur de l'atelier d'André Breton, que a modo de gran escaparate reúne 255 obras, entre cuadros, máscaras, piezas oceánicas o precolombinas, cajas con mariposas, objetos encontrados.... Este llamativo conjunto que evoca la segunda habitación del apartamento de la rue Fontaine de París, ocupado por el poeta desde 1922 hasta 1966, fecha de su muerte, ingresó en el museo mediante dación en 2003.

\section{Las distintas formas de narrar historias dentro del museo: los microrrelatos}

En este afán por adecuar los museos a los nuevos tiempos, España tampoco quedaría al margen, como así lo prueba el proyecto llevado a cabo por Manuel Borja-Villel en el Museo Nacional Centro de Arte Reina Sofía (MNCARS).

Ubicado en el antiguo Hospital de San Carlos, que Francisco Sabatini construyó a finales del siglo XVIII, el "Reina Sofía" abría sus puertas al 


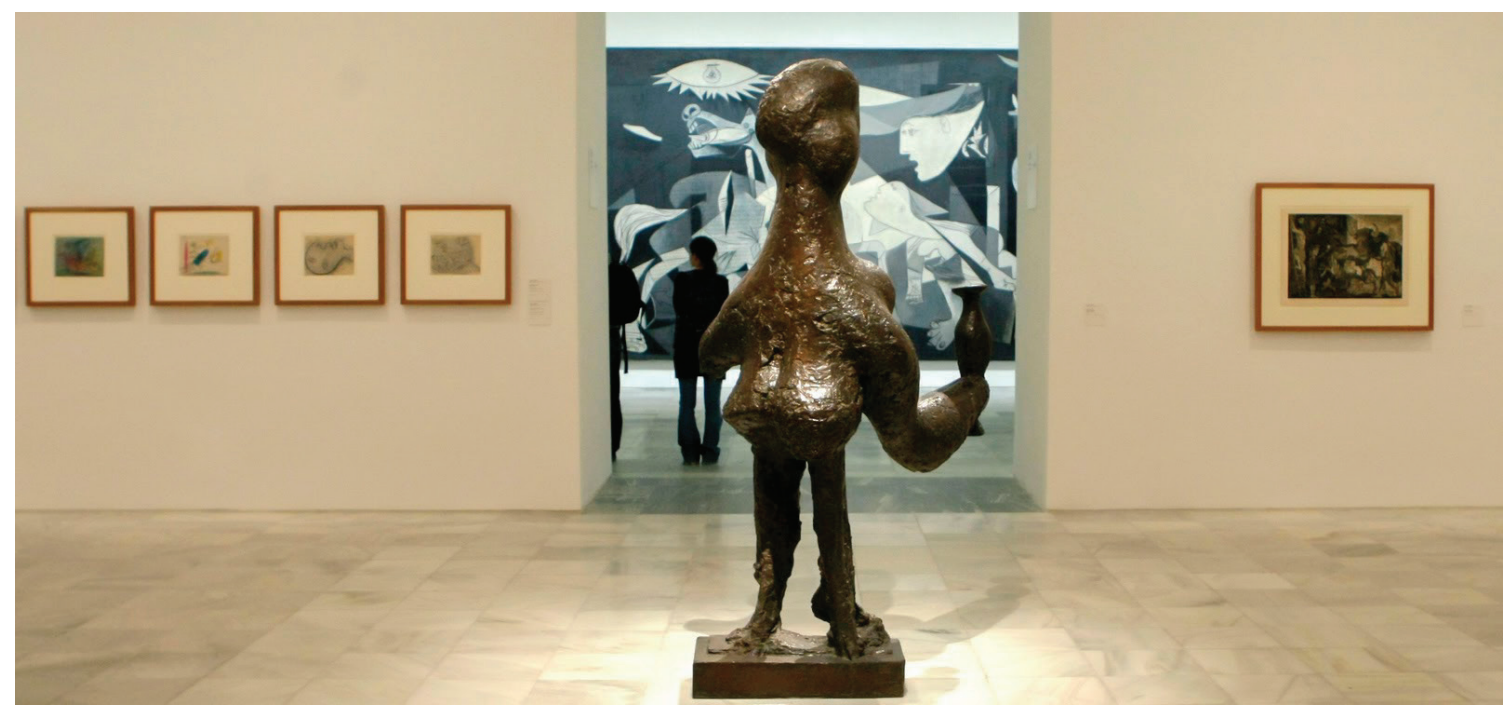

Fig. 5. La Dama oferente de Picasso y el universo Guernica. Museo Nacional Centro de Arte Reina Sofía. Madrid. [Imagen: La otra orilla, Ramon Rozas.blogspot.com.es, 2011/11/21]. [URL:http://ramonrozas. blogspot.com.es/2011/11/la-otra-orilla.html].

público en 1990. Dos años después su colección de arte contemporáneo se enriquecía con la llegada del Guernica de Picasso, que de inmediato se convirtió en el eje sobre el que bascula todo el discurso. Desde 2005, el MNCARS cuenta con el edificio Jean Nouvel, que ha venido a solventar las necesidades de espacio de la institución.

En lo que a la presentación de sus colecciones se refiere, durante buena parte de su trayectoria el museo madrileño se ha mantenido fiel a la museografía formalista y lineal que el MoMA acuñó en los años cuarenta, lo que justifica que el arte contemporáneo quedara constreñido a la pintura y a la escultura, frente a otros lenguajes, como la imagen en movimiento, que se reducían a la mínima y rara vez aparecían mezclados. Por ejemplo, en las salas dedicadas al Surrealismo los "objetos surrealistas" se mostraban aislados en una pequeña habitación, mientras que las pinturas se exhibían en otro espacio separado a su vez de la sala que contenía fotografías o películas. Una organización que daba a entender que los artistas trabajaban en disciplinas cerradas, cuando la realidad del movimiento fue mucho más compleja, con continuas contaminaciones y colaboraciones en obras colectivas (Tejeda 2009: 46).

Así estaban las cosas cuando, en enero del 2009, Manuel Borja-Villel desembarcó en el "Reina Sofía", tras ser elegido como director en un concurso internacional. Traía a sus espaldas una dilatada experiencia profesional en el ámbito de los museos de arte contemporáneo, como lo prueba su labor durante ocho años al frente de la Fundación Antoni Tàpies de Barcelona (1990-1998), y su posterior nombramiento como director del Museo de Arte Contemporáneo de Barcelona (MACBA) (19982008).

Desde el primer momento, quedó claro que pensaba afrontar este reto desde planteamientos nada ortodoxos; algo lógico si pensamos que el sustrato teórico que rige sus actuaciones hunde sus raíces en la "museología crítica", corriente que conoció y asimiló, allá por los años ochenta, durante su periodo de formación en los Estados Unidos.

El primer dato a tener en cuenta para entender sus intervenciones en el MNCARS, es el peso que han tenido las circunstancias específicas del propio museo. Por un lado, los "espacios", que dificultan la organización de los circuitos, tanto los del antiguo hospital con sus larguísimas y rígidas galerías en torno al claustro, como los del edificio Nouvel, tan poco acordes a su función. Y por otro, la "colección", con sus grandes lagunas históricas, consecuencia del secuestro que durante décadas padeció la modernidad en España; vacíos que, como le ocurrió a la Tate Modern, lo inhabilitan para ser un museo enciclopédico. De lo que no hay duda es que ambos museos se sitúan en el polo opuesto al MoMA o al Pompidou, instituciones que por la riqueza de sus colecciones permiten al visitante hacer una lectura completa y lineal de la historia del arte contemporáneo. 
A pesar de esto, y según contaba Borja-Villel (2011), actualmente el MNCARS cuenta con unas colecciones muy idóneas para dar forma a una narrativa "archipiélago", donde piezas emblemáticas, pensemos, por ejemplo, en El Guernica de Picasso (Fig. 5), conviven con otras menos relevantes, pero de gran valor documental, que van generando relatos, ya no exclusivamente artísticos, pues "la pieza", como obra de arte en sí misma, cede su protagonismo "a la idea" o concepto buscado por el responsable del discurso. En este sentido, aunque las colecciones del museo madrileño mantengan, como la Tate Modern, el tradicional esquema de carácter cronológico ${ }^{3}$, lo que se va generando en las salas son islas de contenido que unas veces siguen un hilo conceptual, formal o temático, y otras se centran en una circunstancia histórica.

Estas mini exposiciones de tesis, estas "micronarrativas" o "micro-relatos", en donde no suelen faltar vitrinas con publicaciones o películas documentales que recrean el contexto histórico y social del momento, propician el encuentro entre diferentes autores y diferentes lenguajes (Fig. 6). Y lo que es más importante, ofertan al visitante un variado abanico de enfoques y puntos de vista (Hernández 1998), que, dependiendo del modo en que los responsables del museo relacionen unas piezas con otras y las hagan dialogar entre sí (da igual que sean pinturas, esculturas, maquetas arquitectónicas, libros, fotografías, películas, fragmentos musicales, revistas..., o que pertenezcan a otra época), irán contando distintas historias, pues en su propia esencia está el ser algo vivo, abierto y en continua revisión.

A esto se une una variante más: la posibilidad de que el visitante construya libremente su recorrido, adaptándolo a sus intereses. Por ejemplo, cuando se sale del ascensor en la segunda planta, unos discretos carteles pegados a las ventanas brindan al visitante la posibilidad de dirigirse al Guernica por dos rutas alternativas: a través de las salas dedicadas al cubismo si rodea el patio por la derecha, o a través del surrealismo si lo hace por la izquierda.

Por tanto, habría que preguntarse ahora si la recepción de estos mensajes, por parte del público, realmente funciona. Hemos podido comprobar que, aunque el contenido de los "micro-relatos" del MNCAR resulte en ocasiones extraño o desconcertante, los visitantes que buscan algo "diferente" suelen percibirlos con agrado y curio-

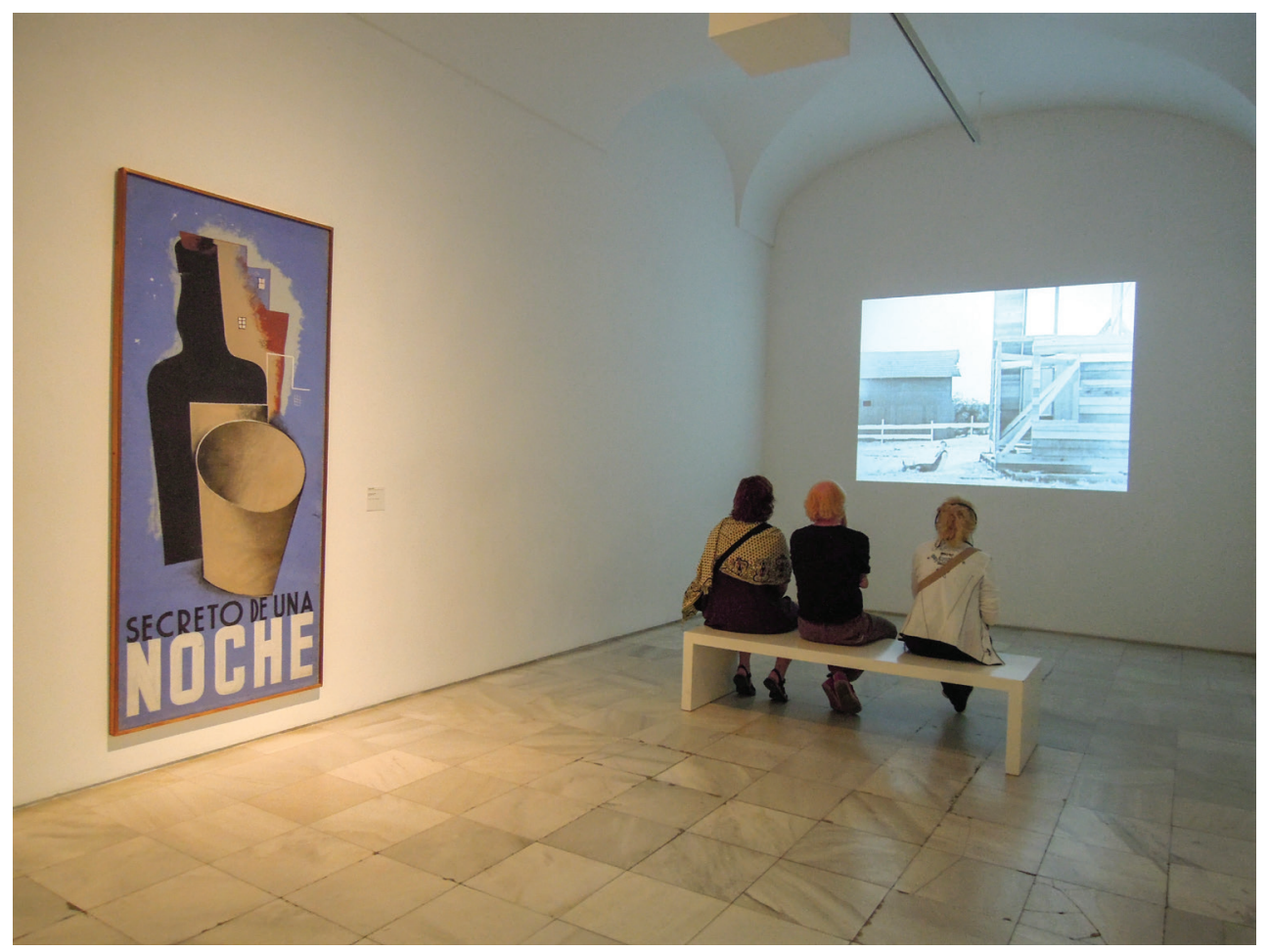

Fig. 6. Sala 210: "La ruptura cubista del espacio". Museo Nacional Centro de Arte Reina Sofía. Madrid. (Foto de Laura Arias, 2014). 
sidad, atrapados por la versatilidad de los temas y géneros que conforman las historias. Pero la mayoría de las veces se quedan ahí, en la percepción sensitiva, más o menos atractiva, chocante u original, sin que esto signifique que han entendido lo que a través de ellos pretende contarles el museo.

El problema se agudiza cuando el visitante (iniciado o no) quiere saber más, cuando necesita comprender dicho discurso, pues intuye que detrás de la mera puesta en escena hay información, sugerencias, guiños..., a los que no consigue acceder. Pues ni se le han facilitado las claves, ni el brevísimo texto de sala le resulta suficiente para poder descubrir las reglas de este juego erudito y pleno de modernidad. Al final, el visitante acaba marchándose con una cierta desazón y con la sensación de que algo falla en las estrategias de presentación de las colecciones.

Quizá la causa haya que buscarla en que, a veces, los responsables del museo, tan centrados en la búsqueda de nuevos relatos o de nuevos enfoques, olvidan que el fin último de todas sus actuaciones ha de ser el público. Y, sin embargo, ¿dónde encajaría ese público, sea cual sea su formación e intereses, en un discurso como éste?

La obra de arte no es algo cerrado, sino abierto, y su red de significados se perfila precisamente en el contexto de la exposición. [...] Si ha de ser un centro de creación activo, el museo no puede dejar de construirse, destruirse y reconstruirse continuamente. No puede ser una mera acumulación, sino que debe ser hostil a ésta. Debe perder continuamente sus fines para poder asumir otros (Borja-Villel 1995: 212).

Argumentos como éste son los que posiblemente han llevado a Isabel Tejeda (2009:49) a prevenir del riesgo que se corre si esta forma de narrar acaba sustituyendo la autonomía artística por la curatorial, y si se utilizan las obras como mera ilustración de las argumentaciones, con el consiguiente "elitismo" de la visita. Para evitar esto es imprescindible una buena señalización, así como la presencia de unos recursos textuales "claros" que ayuden al visitante (especializado o no) a encontrar las claves para una más fácil circulación por las salas y una mejor comprensión de los contenidos.

Concluimos nuestras reflexiones recurriendo de nuevo a Paul Valéry (1999: 139-140), cuando, al pasear por un museo, nos advertía del riesgo que suponía enfrentarse a esas piezas descontextualizadas y frías desde la mera "erudición", pues lo erudito cierra todo resquicio a la emoción:

En materia de arte la erudición es una especie de derrota: aclara justo aquello que no es lo más delicado, y ahonda en lo no esencial. Sustituye la sensación por sus hipótesis, y la presencia de la maravilla por su prodigiosa memoria; y añade al inmenso museo una biblioteca ilimitada. Venus vuelta documento.

Es cierto que, cuando Valéry habla de "erudición”, se refiere a ese pilar básico del saber decimonónico que es el saber positivista y acumulativo; para él, el más lamentable de los vicios. Sin embargo, aunque ahora nuestro contexto sea diferente, no podemos dejar de preguntarnos con cierta inquietud si, en los albores del siglo XXI, el museo de arte moderno vive otro momento de dogmatismo erudito, muy diferente sin duda al fraguado en el siglo de las luces, pero igualmente tiránico para el público.

\section{Notas}

1. En 1927, Barr viajó a Europa conociendo movimientos como De Stijl holandés, la Bauhaus alemana y el constructivismo ruso. Esto reforzó su idea de que un museo de arte moderno debía acoger las diversas creaciones visuales de los artistas y artesanos de nuestro tiempo, desde pintura, escultura o arquitectura, a diseño industrial, fotografía, cine, teatro o música.

2. La Tate Gallery de Londres actualmente se mantiene como museo de bellas artes, albergando arte internacional desde el renacimiento hasta principios del siglo XX, y dando gran protagonismo al arte británico. La Tate Modern, sin embargo, se centra en el arte contemporáneo internacional, acogiendo algunas obras de autores británicos. 
3. En el "Reina Sofía" el discurso cronológico se articula a partir de 1881, fecha del nacimiento de Picasso. Un relato que, en la segunda planta, nos lleva de la modernidad al final de la guerra civil española (19001939), y, en la cuarta, nos adentra en la posmodernidad (1945-1960). Relato que se completa en el edificio Nouvel, que acoge las neo vanguardias (1962-1982).

\section{REFERENCIAS Bibliográficas}

Adorno, Th. W. (2008): Museo Valéry Proust. Crítica de la Cultura y sociedad I. Prismas. Sin imagen directriz [1977], Akal, Madrid: 159-170.

BArR, A. H. (1989): La definición del Arte Moderno (I. Sandler, A. Newman, eds.), Alianza Forma, Madrid. Baudrillard, J. (1978): El efecto Beaubourg. Cultura y simulacro, Editorial Kairós, Barcelona: 77-99.

Bolaños, M. (2000): El Museo a la intemperie, Museo, 5: 11-24.

Bolaños, M. (2002): La memoria del mundo. Cien años de museología 1900-2000, Trea, Gijón.

Bolaños, M. (2006): El museo y la vanguardia: pequeña historia de una rebelión en tres episodios, Artes, La Revista, 12, vol. 6 (julio-diciembre): 3-14.

Borja-Villel, M. (1995): Los límites del museo, Els Limits del museu, Fundació Antoni Tàpies, Barcelona (15/03/1995- 4/06/1995): 212-213.

BorJa-Villel, M. (2011): Conferencia perteneciente al ciclo "La maestría es un grado", Facultad de Geografía e Historia, Universidad Complutense de Madrid, 27 de abril.

Hernández Hernández, F. (1994): Manual de Museología, Síntesis, Madrid.

Hernández Hernández, F. (1998): El museo como espacio de comunicación, Trea, Gijón.

Layuno Rosas, M.A. (1997): Exponerse o ser expuesto (La problemática expositiva de las vanguardias históricas), en Espacio, Tiempo y Forma, serie VII, $\mathrm{H}^{\mathrm{a}}$ del Arte, t. 10: 331-354.

LORENTE, J.P. (2006): Nuevas tendencias en teoría museológica: a vueltas con la museología crítica. Museos. es. Revista de la Subdirección General de Museos Estatales, no 2: 24-33. [URL: http://www.mecd.gob. es/cultura-mecd/dms/mecd/cultura-mecd/areas-cultura/museos/mc/mes/revista-n-2-2006/desdemuseorev02/Rev02_Jesus-Pedro_Lorente.pdf]. Acceso el 12/03/2014.

Lorente, J.P. (2008): Los museos de arte contemporáneo. Noción y desarrollo histórico, Trea, Gijón.

MarinetTi, F. T. (1978): Manifiestos y textos futuristas, Ediciones del Cotal, Barcelona: 132-133.

O’Doherty, B. (2011): Dentro del cubo blanco. La ideología del espacio expositivo [Inside the White Cube, 1986], CENDEAC, Murcia.

PADRó, C. (2003): La museología crítica como una forma de reflexionar sobre los museos como zonas de conflicto e intercambio. Museología crítica y arte contemporáneo (J.P. Lorente, dir.), Prensas Universitarias, Zaragoza: 51-70.

TeJeda MarTín, I. (2009): Una nueva museografía para un nuevo siglo: las colecciones permanentes de los museos de arte contemporáneo. Revista de Museología, no 45: 39-49.

VALERY, P. (1999): Le problème des musées, Le Gaulois, 4 de abril de 1923. Piezas sobre arte (J. L. Arántegui, ed.), Visor, La balsa de la Medusa, 100, Madrid: 137-140.

Zubiaur Carreño, F. J. (2004): Curso de Museología, Trea, Gijón. 